\title{
Aumento del antígeno prostático específico en hipertiroidismo
}

\author{
C. LÓPEZ-IBOR ALCOCER, J. M ORERA MONTES*, \\ A. Martín GonzÁlez, M. Yagüe ArenAS \\ Residente de $3^{*}$ año. *M édico de Familia. \\ Centro de Salud V Centenario. San Sebastián de los Reyes. Madrid
}

\section{RESUMEN}

Comentamos el caso clínico de un paciente con antecedentes de hiperplasia prostática intervenida quirúrgicamente que presenta, años después, un marcado aumento del antígeno prostático específi co (PSA). Este incremento se produce en el contex to de un episodio de hipertiroidismo. Discutimos la posible asociación entre el aumento del PSA y en fermedad tiroidea.

Palabras clave: Antígeno prostático específico (PSA). Hipertiroidismo.
Increase of the specific prostatic antigen in a pa tient with hyperthyroidism

\begin{abstract}
We comment the clinical case of a patient with antecedent of prostatic hyperplasia surgically in tervened that presents later years a marked in crease of the prostatic specific antigen (PSA). This increment takes place in the context of a hyperthy roidism episode. We discuss the possible associa tion between the increase of the PSA and thyroid illness.
\end{abstract}

Key words: Prostatic specific antigen (PSA). Hyperthyroidism.

\section{INTRODUCCIÓN}

Las principales indicaciones del Antígeno Prostático Específico (PSA) son: como método de screening diagnóstico de patología prostática maligna, diagnóstico de recidivas tumorales y como seguimiento durante el tratamiento de dicha patología.

Existen discrepancias en la indicación de medición de niveles del PSA como técnica de screening para la detección precoz del cáncer de próstata, así por ejemplo la American Cancer Society recomienda que tanto el PSA, como el tacto rectal deben realizarse anualmente desde los cincuenta años, a todos aquellos varones que tengan por lo menos diez años de expectativa de vida, y en me- nores de alto riesgo ${ }^{1}$ mientras que la U.S. Preventi ve Services de la Task Force no recomienda ni el tacto rectal, ni la determinación del PSA para el screening del cáncer de próstata.

El aumento del PSA, además de producirse en patología prostática, tanto benigna como maligna, se puede producir tras métodos diagnósticos y terapéuticos de la próstata (resección transuretral ${ }^{2}$ ) pero también es posible encontrar elevación del PSA en otras patologías glandulares.

\section{CASO CLÍNICO}

Varón de 60 años con antecedentes de tabaquismo (consumo mayor de 30 cigarrillos/día, equiva-

Aceptación: 26/11/01 
lente a 60 paquetes-año) de más de 40 años de evolución, adenoma de próstata intervenido quirúrgicamente mediante resección transuretral en junio'99, insuficiencia venosa crónica, ulcus doudenal, fractura de costilla postraumática en 1998, lumbalgias de repetición, con episodios de ciática, por espondilosis y discartrosis L5 y S1, artrosis cervical con radiculopatía con afectación severa C5, C6 y C7 (diagnosticada mediante electromiograma), y consumo crónico excesivo de alcohol que fue derivado para estudio y tratamiento por Atención Primaria desde el servicio médico de su empresa.

Acude a nuestra consulta por presentar pérdida de peso $(17 \mathrm{~kg})$ de dos meses de evolución, fuertes calambres musculares, astenia y no anorexia. Epigastralgia sin pirosis y pérdida de fuerza en la micción. No presenta alteración del ritmo intestinal, ni otros síntomas acompañantes.

A la exploración destacaba un buen estado general, buen nivel de hidratación, nutrición y perfusión. No se apreciaron lesiones cutáneas ni temblor fino distal. No adenopatías. En cuello no se palparon masas, adenopatías ni nódulos tiroideos ni tampoco bocio. La exploración cardiaca pulmonar, abdominal y neurológica fueron normales, miembros sin signos de trombosis venosa profunda.

Pruebas complementarias. Hemograma: hematíes 4,7 x 10\% $/ \mu \mathrm{L}(4,3-5,9)$, hemoglobina $15 \mathrm{~g} / \mathrm{dl}$ (13,7-17,7), hematocrito 45\% (41,4-53), VCM

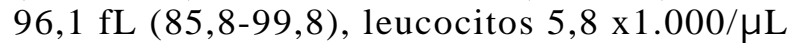
(3,6-10,5) fórmula normal, plaquetas 146.000 $\mathrm{x} 1.000 / \mu \mathrm{L}(132-334), \mathrm{VSG} 18 \mathrm{~mm}(2-12)$, Na 148 mmol/L (136-145), albúmina 4,3 g/dl (3,4-4,8), resto de bioquímica normal, incluidas enzimas hepáticas. Proteinograma normal. Hormonas tiroideas con TSH suprimida: <0,01 mU/ml $(0,40-$ 4,60), T4: 2,72 ng/dl (0,75-2,00). PSA 34 ng/mL (0,00-4,00). Se repite nueva analítica ante la supresión de TSH con niveles de T4 ligeramente aumentados y presentar clínica compatible con hipertiroidismo, así como nueva determinación de PSA: TSH < 0,01 mU/ml, T4 2,3 ng/dl, T3 1,68 ng/dl (0,65-1,69), PSA 38 ng/mL. Anticuerpos antitiroideos (TPO): positivos.

Ante la posibilidad de que la clínica de astenia y pérdida de peso fuese debida, no a un hipertiroidismo, sino a patología digestiva (tenía epigastralgia y antecedente de ulcus duodenal) y por la posible patología prostática (marcado aumento del PSA), solicitamos: gastrodudenoscopia, que el servicio de digestivo informa como normal. Rx de tórax con dudosa imagen nodular en campo superior de pulmón derecho, que en estudio radiológico posterior no se confirma. Rx simple de abdomen donde aparece una dudosa imagen nodular mal definida, de $5 \times 5 \mathrm{~cm}$ de diámetro en hipocondrio izquierdo, que en nueva Rx se informa como posible quiste sub- frénico, por lo que se solicita ecografía abdominal donde no se aprecian lesiones sugestivas de quiste subfrénico ni lesiones ocupantes de espacio, resto de la ecografía normal. Ecografía prostática: parénquima homogéneo con pequeño quiste y cápsula íntegra. Volumen $38 \mathrm{cc}$, vesículas seminales aumentadas de tamaño. $1^{\circ}$ biopsia de próstata, resultado no concluyente (alguna atipia). Nueva biopsia: negativa para 7 muestras. Se remite a endocrino para valoración y control de hipertiroidismo con gran expresión clínica pero con discretas alteraciones analíticas.

Episodio de coluria sin acolia tras un mes desde el inicio del tratamiento con neotomizol con analítica: PSA 3,2 ng/mL, glu $115 \mathrm{mg} / \mathrm{dl}$ (70-110), Bb $1,6 \mathrm{mg} / \mathrm{dl}(0,1-1,2), \mathrm{Bb}$ esterificada $0,8 \mathrm{mg} / \mathrm{dl}$ (0,01-0,2), GOT $68 \mathrm{Ul} / \mathrm{L}$ (10-40), GPT $136 \mathrm{Ul} / \mathrm{L}$ (10-40), GGT 569 Ul/L (10-50), FA 609 Ul/L. TSH $<0,01 \mathrm{mU} / \mathrm{ml}$, T4 2,3 ng/dl. Serología a virus hepatotropos: negativa. Se suspende neotomizol y se sustituye por tirodril por colestasis extrahepática secundaria al tratamiento, normalizándose posteriormente las enzimas hepáticas. Ecografía y nueva analítica hepática normales. Gammagrafía tiroidea: mínimo bocio y captación compatible con hipertiroidismo.

\section{DISCUSIÓN}

Se trata de un varón que presenta un cuadro de hipertiroidismo con elevación marcada de los niveles de PSA. Se descarta la posibilidad de que este aumento se debiera a patología prostática y hemos analizado, mediante revisión bibliográfica la posibilidad de que fuese debido a patología tiroidea.

A principios de los años setenta se identificaron, mediante técnicas inmunológicas, a partir de plasma seminal, tres proteínas específicas de tejido prostático $^{3}$ (seminoproteína, proteína E1 y proteína P30) pero que dadas sus características físicas y bioquímicas similares, se consideró como una única proteína, que fue purificada en 1979 por Wang et al. Estos autores demostraron su relación con el cáncer de próstata, denominándola antígeno pros tático específico (PSA). Esta proteína está codificada por el gen hKLK3 que pertenece al grupo de proteínas que codifican las kalicreínas tisulares humanas (pancretorrenal hK1 y glandular hK2), y que son un grupo de proteasas que generan quininas o péptidos vasoactivos a partir de quininógeno.

El PSA se sintetiza en retículo endoplasmático rugoso del citoplasma de las células del epitelio columnar de las glándulas prostáticas y glándulas periuretrales. Su estructura bioquímica está formada por un monómero de 237 aminoácidos con múltiples enlaces disulfuro en su forma primitiva. Dicha secuencia de aminoácidos es homóloga con el resto 
de kalicreínas (un $64 \%$ con hK1 y un $80 \%$ con hK2), que se producen en glándulas salivares, páncreas y riñón.

Una vez sintetizado y almacenado, el PSA es liberado a la luz glandular en su forma activa con capacidad proteolítica, alcanzando concentraciones en el fluido seminal un millón de veces superior a las de suero $(0,5-5 \mathrm{mg} / \mathrm{ml})$. Los niveles de dicho antígeno, determinados mediante técnicas inmunológicas, suelen encontrarse elevados en neoplasias malignas de próstata, aunque también en tumoraciones malignas de mama, páncreas, patología benigna y tras exploraciones de próstata.

La función fisiológica del PSA es la licuefacción del coágulo seminal a través de la proteólisis de la fibronectina soluble y semenogelinas I y II en pequeños péptidos, que incrementan la motilidad de los espermatozoides, así como la liberación de una sustancia quinina-like que actúa sobre la fertilización.

A partir de 1996 se detectó mRNA del PSA mediante la técnica de reacción de transcriptasa inversa de la cadena de polimerasa (RT-PCR), en treinta tumores primarios de mama y en otros tejidos no patológicos ${ }^{4}$. Recientemente se ha demostrado que hK2 se expresa en las células T-47D del cáncer de mama tras la estimulación con hormonas esteroideas ${ }^{5}$. La línea celular del carcinoma mamario de la mujer produce hK2 así como PSA, pero es necesario establecer el papel de esta kalicreína en el tejido mamario no patológico, en la enfermedad quística de la mama así como en la neoplasia de mama. Posteriormente, se ha postulado que dichas proteínas plasmáticas pueden estar asociadas a un pronóstico favorable del carcinoma de mama ${ }^{6}$. Tanto el tejido tumoral como la secreción normal de la mama, obtenidos mediante punción aspiración con aguja fina, contienen hK2, y la medición cuantitativa es directamente proporcional a la expresión de PSA y receptores de hormonas esteroideas. Se sugiere la posibilidad de que hK2 sea un marcador de acción de hormonas esteroideas sobre el tejido mamario. El grupo del Mount Sinai Hospital, demuestra mediante un estudio caso-control, que en algunas mujeres sometidas a hiperestimulación androgénica, como en el síndrome de ovario poliquístico (SOP), existen valores del PSA superiores ${ }^{7}$. Una correlación similar se encontró entre niveles de PSA urinarios y glucurónico 3-alfa androstediona sérica así como entre PSA urinario y testosterona sérica. El resultado del estudio indica que la determinación de PSA urinario, y posiblemente hK2 urinario, puedan ser en un futuro, marcadores de hiperandrogenismo en mujeres con SOP.

Se ha demostrado mediante experimentación animal (ratones) la aparición en dichos animales de carcinomas de glándulas salivares de origen ductal así como carcinomas del tracto gastrointestinal de origen estromal, de distintos grados de diferen- ciación, tras la administración de un gen productor del PSA mutado mediante técnicas transgénicas ${ }^{8}$.

Dentro del grupo de tejidos patológicos donde se describe positividad a PSA se incluye el adenocarcinoma pulmonar. También la beclometasona, glucocorticoide utilizado en el tratamiento de la neoplasia, produce un efecto activador sobre la producción genética de $\mathrm{PSA}^{9}$. La expresión del PSA, en este caso, podría estar mediada por la administración exógena de beclometasona.

Otro tejido neoplásico con positividad para PSA, ha sido el neuroblastoma ${ }^{10}$ (dos casos). Aunque su significado se desconoce, se postula la hipótesis de que esta proteasa sérica producida por el tumor esté relacionada con el crecimiento de células tumorales, aceptando las nuevas funciones biológicas de esta proteína kalicreína-like.

También se describe el antígeno prostático específico de membrana (PSMA) ${ }^{11}$, un tipo de proteína de transmembrana (tipo II), que en un principio se pensó que se producía únicamente en tejido prostático. Estudios recientes han demostrado que PMSA se produce también en células endoteliales implicadas en la neovascularización tumoral no prostática.

Por último, utilizando la técnica de reacción de transcriptasa inversa de la cadena de polimerasa (RT-PSA), se ha identificado extracto de RNA del PSA en 26 diferentes tejidos y se han encontrado genes de PSA y hK2 en tiroides ${ }^{12}$, tanto en casos de patología benigna como maligna. Por imnunohistoquímica se localiza PSA en las células oxifílicas de dicho tejido glandular. Estos hallazgos podrían justificar el que se produzcan incrementos del PSA en los casos de patología tiriodea.

Existe la evidencia creciente que el carcinoma de próstata esté determinado por un complejo sistema de eventos genéticos, como interacciones paracrinas, hormonales y factores dietéticos, como son los andrógenos, vitamina $\mathrm{D}$, y retinoides ${ }^{13}$. Las hormonas tiroideas influyen también en el crecimiento y diferenciación de las células del carcinoma prostático. Se ha comprobado la inclusión de T3 en las células malignas, que la 3,5,3' triiodotironina (T3) incrementa la dependencia androgénica del PSA demostrando la existencia de un elemento T3 en el gen del PSA (en la región del cordón promotor 5') y que el gen del PSA es regulado por T3 durante la transcripción de dicho gen ${ }^{14}$.

En nuestro caso, habiéndose descartado de forma razonable, tanto la recidiva de patología benigna prostática (hiperplasia), como la aparición de patología maligna, es posible que el incremento del PSA esté en relación con la patología tiroidea.

\section{CONCLUSIÓN}

El antígeno prostático específico es una proteína plasmática, desarrollada e incorporada a la 
práctica clínica en la década de los 70, marcador de tejido prostático, cuyos niveles suelen encontrarse elevados en neoplasias malignas de próstata, aunque también en tumoraciones malignas de mama, tracto gastrointestinal, patología benigna y resecciones transuretrales de próstata, y como en nuestro caso, es posible encontrarlo elevado en patología tiroidea.

\section{CORRESPONDENCIA:}

Cristina López-Ibor Alcocer

C/ Hoyos del Espino, 25

28035 Madrid

e-mail: cliaa@eresmas.com

\section{Bibliografía}

1. Thompson IM, Foley J. Sreening for Prostate Cancer. Current Clinical Urology: Management of Prostate Cancer. Totowa, NJ: Ed. E. A. Klein Humana Press Inc., 1998. p. 71-85.

2. Heung YM, Walsh K, Sriprasad S, Mulvin D, Sherwood RA. The detection of prostate cells by the reserve transcription-polymerase chain reaction in the circulation of patients undergoing transurethral resection of the prostate. BJU Int 2000; 85 (1): 65-9.

3. Morote Robles J. Valor del antígeno prostático específico en el diagnostico y evolución de la hiperplasia benigna de próstata. Medicine. Hiperplasia beninga de próstata. 1997; $7^{\circ}$ serie. Num extraordinario: $28-35$.

4. Zarghami N, Diamandis EP. Detection of prostate-specific antigen mRNA and protein in breast tumors. Clin Chem 1996; 42 (3): 361-6.

5. Magklara A, Scorilas A, Lopez-Otin C, Vizoso F, Ruibal A, Diamandis EP. Human glandular kallikrein in breast milk, amniotic fluid, and breast cystic fluid. Clin Chem 1999; 45(10): 1774-80.

6. Black MH, Magklara A, Obiezu C, Levesque MA, Sutherland DJ, Tindall DJ, et al. Expression of a prostate-associated protein, human glandular kallikrein (hK2), in breast tumours and in normal breast secretions. Br J Cancer 2000; 82 (2): 361-7.

7. Obiezu C, Scorilas A, Magklara A, Thornton MH, Wang CY, Stanczyk FZ, et al. Prostate-specific antigen and human glandular kallikrein 2 are markedly elevated in urine of patients with polycystic ovary syndrome. J Clin Endocrinol Metab 2001; 86 (4): 1558-61.
8. Schaffner DL, Barrios R, Shaker MR, Rajagopalan S, Huang SL, Tindall DJ, et al. Transgenic mice carrying a PSArasT24 hybrid gene develop salivary gland and gastrointestinal tract neoplasms. Lab Invest 1995; 72(3): 283-90.

9. Zarghami N, D’Costa M, Tsuyuky D, Asa SL, Diamandis EP. Expression of the prostate specific antigen gene by lung tissue. Clin Cancer Res 1997; 3(7): 1201-6.

10. Mannello F, Malatesta M, Luchetti F, Papa S, Battistelli S, Gazzanelli G. Inmunoreactivity, ultrastructural localization, and transcript expression of prostate-specific antigen in human neuroblastoma cell lines. Clin Chem 1999; 45 (1): 78-84.

11. Chang SS, O'Keefe DS, Bacich DJ, Reuter VE, Heston WD, Gaudin PB. Prostate-specific membrane antigen is produced in tumor-associated neovasculature. Clin Cancer Res 1999; 5(10): 1674-81.

12. Magklara A, Cheung CC, Asa SL, Diamandis EP. Expression of the prostate specific antigen and human kallikrein 2 in the thyroid gland. Clim Chim Acta 2000; 300 (1-2): 171-80.

13. Esquenet M, Swinnen JV, Heyns W, Verhoeven G. Triiodothyronine modulates growth, secretory function and androgen receptor concentration in the prostatic carcimoma cell line LNCaP. Mol Cell Endocrinol 1995; 109 (1): 105-11.

14. Zhu W, Young CY. Androgen-Dependent transcriptional regulation of the prostate-specific antigen gene by thyroid hormone 3,5,3' Triiodothyronine. J Androl 2001; 22 (1): $136-41$. 